NASA Technical Memorandum 89895

4

\title{
Experiments on Dynamic Stiffness and Damping of Tapered Bore Seals
}

\author{
(SASA-TE-89895) EXPERIUENIS CA CYHAMTC \\ STIFFHESS ALD DAMEING CF TAEEEED EORE SEALS \\ (BASA) 13 p Mail: ITIS EC AO2/MF AO1 \\ CSCL 11A Dnclas \\ H1/37 0080142 \\ $\$ 87-23984$
}

David P. Fleming

Lewis Research Center

Cleveland, Ohio

Prepared for the

Vibrations Conference

sponsored by the American Society of Mechanical Engineers

Boston, Massachusetts, September 27-30, 1987

\section{NMSA}


EXPERIMENTS ON DYNAMIC STIFFNESS AND DAMPING OF TAPEREO BORE SEALS

\author{
David P. Fleming \\ National Aeronautics and Space Administration \\ Lewts Research Center \\ Cleveland, ohio 44735
}

\section{ABSIRACT}

Stiffness and damping were measured in tapered bore ring seals with air as the sealed fluid. Excitation was provided by a known unbalance in the shaft which rotated in the test seals. Results were obtained for various seal supply pressures, clearances, unbalance amounts, and shaft speeds. Stiffness and damping varied little with unbalance level, indicating linearity of the seal. Greater vartation was observed with speed and particularly supply pressure. A onedimensional anaiysis predicted stiffness fairly well, but considerably overestimated damping.

NOMENCLATURE

A

B seal damping coefficient

$C_{1}, C_{2}$ entrance and exit radial clearance of concentric sea 1

D seal diameter

$e_{\mu} \quad$ displacement of shaft mass axis from geometric axis

$K$ seal stiffness coefficient

L seal length

$P_{0}, P_{3}$ reservoir and sump pressures

$R \quad$ seal radius

$x, y \quad$ transverse coordinates

$\varepsilon$ eccentricity ratio $A / C_{2}$

$\mu$ fluid viscosity

\$ phase angle

\section{INTRODUCTION}

It is now well-known that annular pressure seals (ring seals) can generate significant lateral forces and that these forces can strongly influence the dynamics of shaft systems. Since the pioneering work of Black (1969), many researchers have been involved in determining the steady state and dynamic properties of seals. Analyses have predicted that tapered bore seals will have a higher stiffness than straight bore seals for both incompresstble and compressible fluids (Fleming, 1977, 1979). Moreover, for compressible fluids, straight bore seals can sometimes have a negative stiffness which is nearly always undesirable. Tapered bore seals have been used successfully where straight bore seals falled. Such an application was the hot gas seal in the space shuttle high pressure oxygen pump. This is a floating ring seal. The low centering forces developed by the stralght bore seal allowed rubbing to occur as the seal attempted to follow shaft excursions; this resulted in rapid seal wear. The higher $f 11 \mathrm{~m}$ forces of the tapered bore seal permitted the seal to follow shaft motions without rubbing, hence eliminating wear.

Experimental results for compressible fluids are just beginning to be published, (Nelson et al. 1986; Fleming, 1986). In the former work, the authors verified the prediction of higher dynamic stiffness for tapered bore seals. Their results, however, were entirely for turbulent flow of the sealed fluid. The latter paper reported steady-state stiffness for laminar flow in tapered bore seals.

The purpose of the present work is to measure the dynamic stiffness and damping of tapered bore seals for laminar flow with air as the sealed fluid. The experimental data will be compared with avallable analysis.

\section{APPARATUS}

The test apparatus, shown in Fig. 1, was originally designed for use with herringbone-grooved journal bearings; its description for that work was given by 
Cunningham et al. (1969). For the present work, as well as that of the previous report for steady state stiffness (Fleming, 1986), the hydrodynamic bearing sleeves were replaced by the tapered-bore seals shown in Fig. 2 The apparatus was further modifled by pro vision of air supply passages to the center section of each seal pair. Air is supplied to the center of the seal and flows out at each end, exhausting into the room. The downstream pressure is therefore always one atmosphere. Pressure taps were provided for measurement of the pressure at the seal entrance (Fig. 1). This pressure measurement was made in the annulus on the outer diameter of the seal insert; it was assumed that air velocity in this annulus and pressure drop from the annulus to the seal entrance were negligible. The herringbone shafts used by Cunningham et a1. (1969) were replaced by smooth shafts having provision for balancing screws in four radial holes at each end of the shaft. Three shafts were made with varying diameters in order to vary the seal clearance. The nominal diameter is $38 \mathrm{~mm}$; the seals are $17.5 \mathrm{~mm}$ long resulting in a length-to-diameter ratio of 0.46 .

As shown in Fig. 1, the shaft is vertical so that no steady load is applied to the seals. The pneumatic loader used in the previous work (Fleming, 1986) was removed. The shaft was rotated by an impulse turbine. Two orthogonally-mounted capacitance distance probes are mounted outboard of each seal pair. They were used to measure the dynamic displacement of the shaft, and also the assembled clearance of the shaft in the seals. Because of slight misalignment of the two seal pairs, the apparent assembled clearance (as measured by the capacitance probes) was slightly less than the nominal clearance. An additional capacitance probe was located where a notch on the shaft passed by once per revolution; this provided a phase reference. Signals from the phase reference probe and from two of the displacement probes were routed to a dual digital vector filter which provided a digital output of shaft speed, vibration amplitude, and phase angle. The digital amplitude and phase data were then transmitted to a computer. The data were read under the control of a FORTRAN computer program, which then reduced the data to provide dynamic stiffness and damping coefficients. The computer provided graphical as well as printed output.

There is no provision for measuring seal leakage. Calculations showed that, for the air pressures used, the flow would be laminar.

\section{EXPERIMENTAL PROCEDURE}

The shaft was unbalanced by turning the balancing screws an appropriate amount. Care was taken to keep the mass axis of the shaft parallel to the geometric axis so that the dynamic displacement would be the same at each seal. Prior to any data runs, each shaft had been carefully balanced in the rig to minimize the residual unbalance.

The air pressure to the seals was set at the desired value. The upper (drive end) seal required a slightly higher pressure than the lower (thrust end) seal to minimize the dynamic shaft misalignment. This misalignment occurs because the shaft mass center is closer to the upper seal, and because of slight (unintentional) variations in seal geometry and alignment. Shaft speed was set to approximately $500 \mathrm{rpm}$ (a speed low enough that dynamic motion was negligible); the amplitude and phase angle resulting were stored by the computer as low speed runout. The runout was subtracted vectorially from subsequent measurements to yield only the dynamic part of the shaft motion. Runout magnitude was typically 0.0003 to $0.0005 \mathrm{~mm}$; this was considerably less than the dynamic response at speeds where data were recorded. Speed was increased in increments and dynamic data acquired as the speed was held steady. After running up and down in speed, the seal supply pressure was reset and the speed sweep repeated.

\section{RESULTS}

Three shafts of different diameters were used in a single set of seals. Table I shows the clearances and clearance ratios obtained. The clearance values are the mean of those measured for the upper and lower seals. The lower seal clearance was measured as $0.0006 \mathrm{~mm}$ less than the upper seal; however, this difference is within the measurement error bound of $0.002 \mathrm{~mm}$. These seals were not the same as used in the previous work (Fleming, 1986) because the seals used previously were accidentally destroyed.

Figures 3 to 6 are representative of the data obtained. Figures 3 and 4 show the measured amplitude and phase angle, corrected for low speed runout and mathematically shifted axially to the center plane of the seal from the probe position. Simple geometric formulas for this have been presented by fleming et a1. (1976). The same reference contains the equations of motion for the four degree of freedom shaft system. Measured amplitude and phase angle (with low speed runout subtracted) were inserted in these equations which were then solved to obtain dynamic stiffness and damping coefficients. Figure 5 shows the dynamic stiffness obtained and Fig. 6 the dynamic damping. Cross-coupled dynamic coefficients cannot be obtained in the present apparatus, since the motion observed is nominally a centered, circular orbit.

Examples of the actual orbits observed on an oscilloscope appear in Fig. 7. Note that for the most part they are quite circular. The bright dot is produced by the phase reference marker on the shaft as it passes the phase reference probe. This probe lies on the $x$-axis of the apparatus. The phase angle is then the angle from the bright dot to the $x$-axis in Fig. 7; it is the angle from the passing of the phase reference mark to the maximum $x$ displacement. One can readily see the change in phase angle from near zero to almost $180 \mathrm{deg}$ as the shaft passes through the critical speed (about $11000 \mathrm{rpm}$ for the conditions of Fig. 7). The experimental data points for stiffness (Fig. 5 is typical) form a fairly smooth curve. The damping results exhibit more scatter (Fig. 6 is typical for damping). There seemed to be no physical reason for the observed scatter in damping data; it was expected that damping values would also ile on a smooth curve. Shaft vibration amplitude, which varies with shaft speed, could conceivably cause a change in damping with speed. As discussed later, however, shaft amplitude seemed to have only a small effect on damping.

Adams and Rashidi (1985) have recognized that stiffness and damping coefficients are often very sensitive to small changes in measured data, which in the present case are shaft amplitude and phase angle. Using this thesis, it was postulated that the seal coefficients to be determined were actually invariant with shaft speed (the analysis used does not predict any variation with speed). The task then was to find those particular stiffness and damping values which, when inserted in the shaft equations of motion, best reproduced the measure amplitude and phase angle. The actual data fitted, rather than amplitude and phase angle, were the orthoganal components of amplitude $A$ $\cos \phi$ and $A$ sin $\phi$. Stiffness and damping coefficients for the two seal pairs (a total of four 
coefficients) were initially chosen as a simple average of the coefficients determined over the speed range. These average coefficients were then used in the rotor equations of motion to calculate expected amplitude components. The coefficients were refined iteratively using a nonlinear least-squares procedure as reported by Isenberg (1979). Results of this procedure are shown in figs. 3 and 4 . These results show that constant stiffness and damping coefficients produce amplitudes and phase angles very close to those measured, except at speeds well above the critical speed. At these high speeds, there is apparently a real decrease in stiffness and damping. This is indicated by the measured amplitude being lower than predicted (tending toward the unbalance eccentricity) and the measured phase angle being higher than predicted (tending toward $180 \mathrm{deg}$ ). This decrease in stiffness and damping at high speed is not predicted by Fleming's (1980) analysis, nor was it observed in the experiments of Nelson et al. (1986). However, analyses and experiments on pressurized gas bearings have shown such decreases, for example, Stiffler and Smith (1975), and Fleming et al. (1977). Figures 5 and 6 show the relationship of the measured stiffness and damping to the least-squares mean.

The results of this curve fitting procedure were encouraging enough that the coefficients thus determined will be used in presenting the remainder of the results of this paper. These are shown in Figs. 8 to 10 where stiffness and damping coefficients are plotted as functions of pressure ratio across the seal.

Figure 8 is for shaft 2 with a radial clearance of $0.026 \mathrm{~mm}$ and a clearance ratio (ratio of inlet to out let clearance) of 2.0. There is little change in stiffness (the lower part of the figure) with pressure ratio. This small variance is also predicted by analysis (Fleming, 1979). The sudden change in the slope of the analytical curve is due to the flow becoming choked above a pressure ratio of 4.8. This behavior may also be occurring in the experimental data; however, there is enough scatter that one cannot say with certainty. The stiffness of the drive end seal is consistently higher than that of the thrust end seal. This could be due to minor geometry differences between the two seals; to the somewhat greater apparent misalignment of the drive end seal; or to the drive turbine augmenting the stiffness of the drive end seal. All of the results are within 30 percent of those predicted by analysis.

The solid symbols are for a shaft unbalance of $7.2 \mathrm{~g} \mathrm{~mm}$, substantially greater than the $4.3 \mathrm{~g} \mathrm{~mm}$ represented by the open symbols. The larger unbalance produced a correspondingly larger amplitude of motion. The measured stiffness is only slightly larger, however. The maximum amplitude observed for both unbalance levels was still in the "small eccentricity" range; the maximum eccentricity ratio $(\varepsilon)$ was 0.5 . Damping coefficients are shown in the upper part of fig. 8. Simllar to the results for stiffness, the amplitude of motion (as influenced by the unbalance level) has only a small effect on damping. Damping increases with pressure ratio as predicted by analysis. The damping values measured, however, are only about half of the predicted values. This is probably due to the limitation of the one-dimensional analysis used. It was shown previously (fleming, 1986) that for turbulent flow the one-dimensional analys is predicts damping coefficients about twice as large as the twodimensional analysis of Nelson (1985). A twodimensional analysis would be expected to yield more accurate results. Nelson's results are only avallable for turbulent flow; however, one would expect the relationship between two-dimensional and onedimensional analyses to be similar for laminar flow. Figure 9 is for shaft 3 , with a clearance of $0.040 \mathrm{~mm}$. Results are generally similar to those for shaft 2; observed stiffness and damping are somewhat higher relative to analysis than for shaft 2 , however. Again, the results show only a small effect from changing the amount of unbalance.

Figure 10 shows data for shaft 1 , with a clearance of $0.014 \mathrm{~mm}$, the smallest tested. The stiffness results are very close to those predicted. The measured damping values are lower, relative to analysis, than for the other shafts. The results of Fig. 10 are consistent with those of Figs. 8 and 9, in that larger clearances produce larger stiffness and damping relative to analysis. The effect of misalignment would be greater for a smaller clearance; on the basis of the present data, however, it cannot be ascertained whether it is this or some other effect causing the change relative to predicted values.

\section{CONCLUDING REMARKS}

Experimental data have been obtained for dynamic stiffness and damping in tapered bore ring seals. Results show that stiffness is fairly well predicted by a one-dimensional analysis. Damping is considerably overestimated by the analysis, however.

\section{REFERENCES}

1. Adams, M.L., and Rashidi, M., 1985. "On the Use of Rotor-Bearing Instability Thresholds to Accurately Measure Bearing Rotodynamic Properties," Journal of Vibration. Acoustics, Stress, and Reliability in Design, Vol. 107, No.4, pp. 404-409.

2. Black, H.F., 1969. "Effects of Hydraulic Forces in Annular Pressure Seals on the Vibrations of Centrifugal Pump Rotors," Journal of Mechantcal Engineering Science, Vol. 11, No. 2, pp. 206-213.

3. Cunningham, R.E., Fleming, D.P., and Anderson, W.J., 1969. "Experimental Stability Studies of the Herringbone-Grooved Gas-Lubricated Journal Bearing." Journal of Lubrication Technology, Vol. 91, No. 1, pp. 52-59.

4. Fleming, D.P., Thayer, W. J., and Cunningham, R.E., 1976. "Experimental Dynamic Stiffness and Damping of Externally Pressurtzed Gas-Lubricated Journal Bearings," NASA TN D-8270.

5. Fleming, D.P., 1979. "Stiffness of Stralght and Tapered Annular Gas Path Seals, " Journal of Lubrication Technology, Vol. 101, No. 3, pp. 349-355.

6. Fleming, D.P., 1980. "Damping in Ring Seals for Compressible Fluids," Rotordynamic Instability Problems in High-Performance Turbomachinery, NASA CP-2133, pD. 169-188.

7. Fleming, D.P., 1986. "Experimental Stiffness of Tapered Bore Seals," Journal of Vibration, Acoustics, Stress, and Reliablitty in Design, Vol. 103, No. 1, pp. 97-94.

8. Isenberg, J., 1979. "Progressing from Least Squares to Bayesian Estimation," ASME Paper 79-WA/DSC-16. 
9. Nelson, C.C., 1985. "Rotordynamic Coefficients for Compressible Flow in Tapered Annular Seals," Journal of Tribology, Vol. 107, No. 3, pp. 318-324.

10. Nelson, C.C., Childs, D.W., Nicks, C., and Elrod, D., 1986. "Theory Versus Experiment for the Rotordynamic Coefficients of Annular Gas Seals: Part 2 - Constant-Clearance and Convergent-Tapered Geometry," Journal of Tribology, Vol. 108, No. 3, pp. 433-438.
11. Stiffler, A.K., and Smith, D.M., 1975. "Dynamic Characteristics of an Inherently compensated, Square, Gas Film Bearing," Journal of Lubrication Technology, Vol. 97, No. 1, pp. 52-62.

TABLE I. - SEAL CLEARANCES AND

CLEARANCE RATIOS

\begin{tabular}{|c|c|c|}
\hline Shaft & $\begin{array}{c}\text { out let } \\
\text { clearance } \\
\mathrm{mm}\end{array}$ & $\begin{array}{c}\text { In let clearance/ } \\
\text { out let clearance }\end{array}$ \\
\hline 1 & 0.014 & 2.9 \\
2 & .026 & 2.0 \\
3 & .040 & 1.6 \\
\hline
\end{tabular}




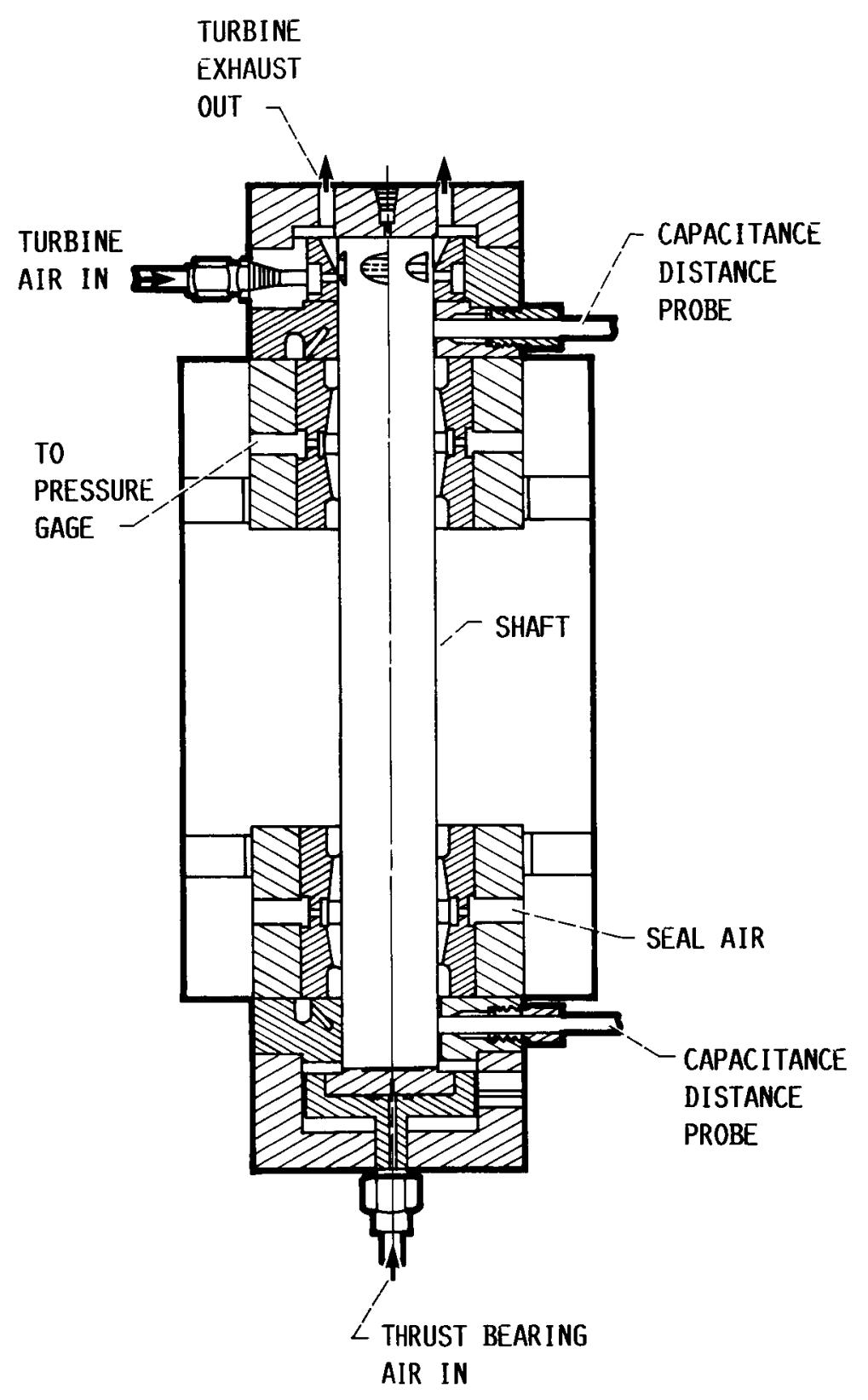

FIGURE 1. - TEST APPARATUS. 


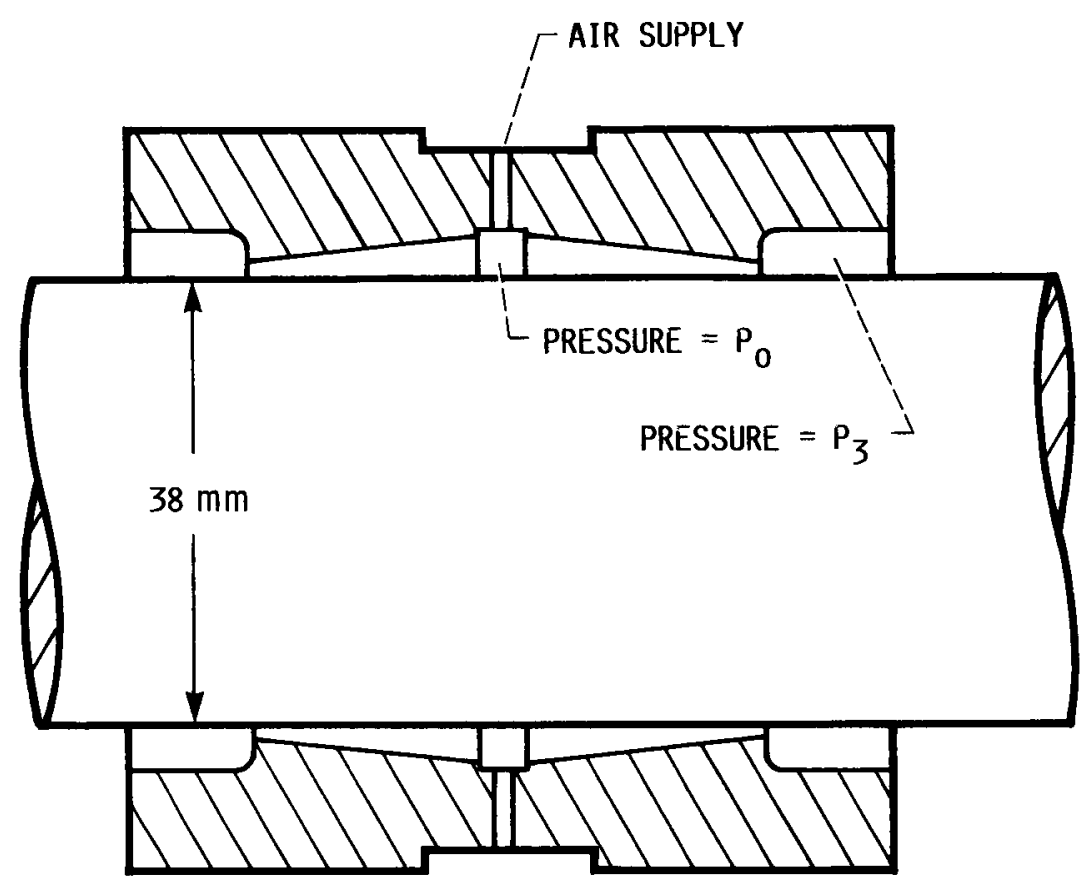

FIGURE 2. - TAPERED BORE SEAL.

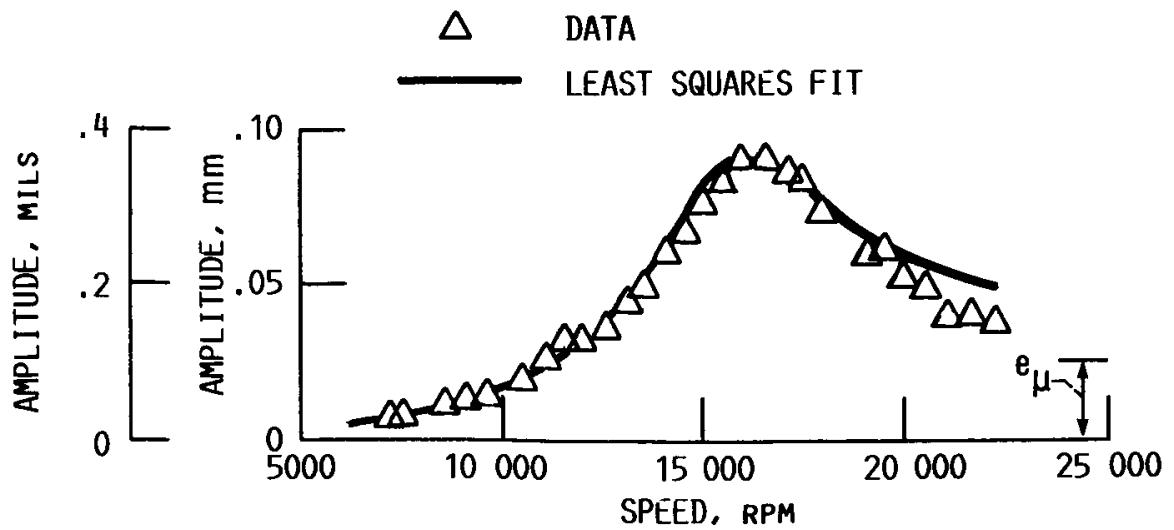

FIGURE 3. - SHAFT AMPLITUDE AT LOWER SEAL. UNBALANCE, $7.2 \mathrm{~g} \mathrm{~mm}$ : PRESSURE RATIO 6.2. 


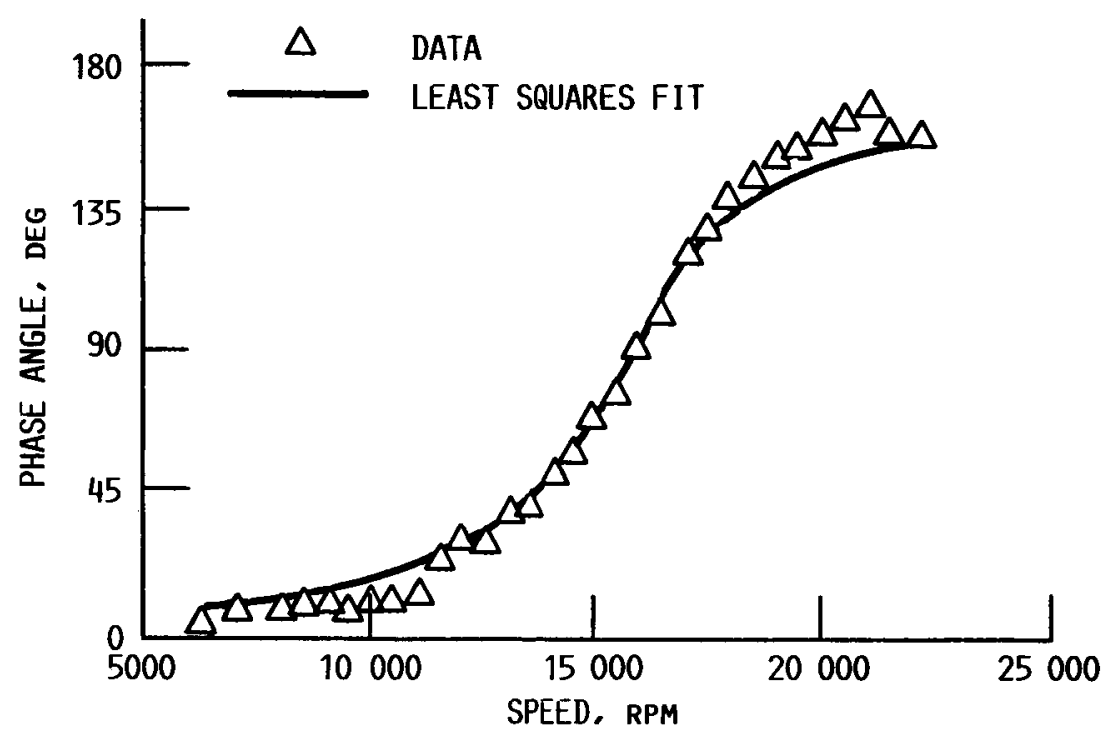

FigURE 4. - PHASE ANGLE AT LOWER SEAL, UNBALANCE, $7.2 \mathrm{~g} \mathrm{~mm}$ : PRESSURE RAT10, 6.2 .

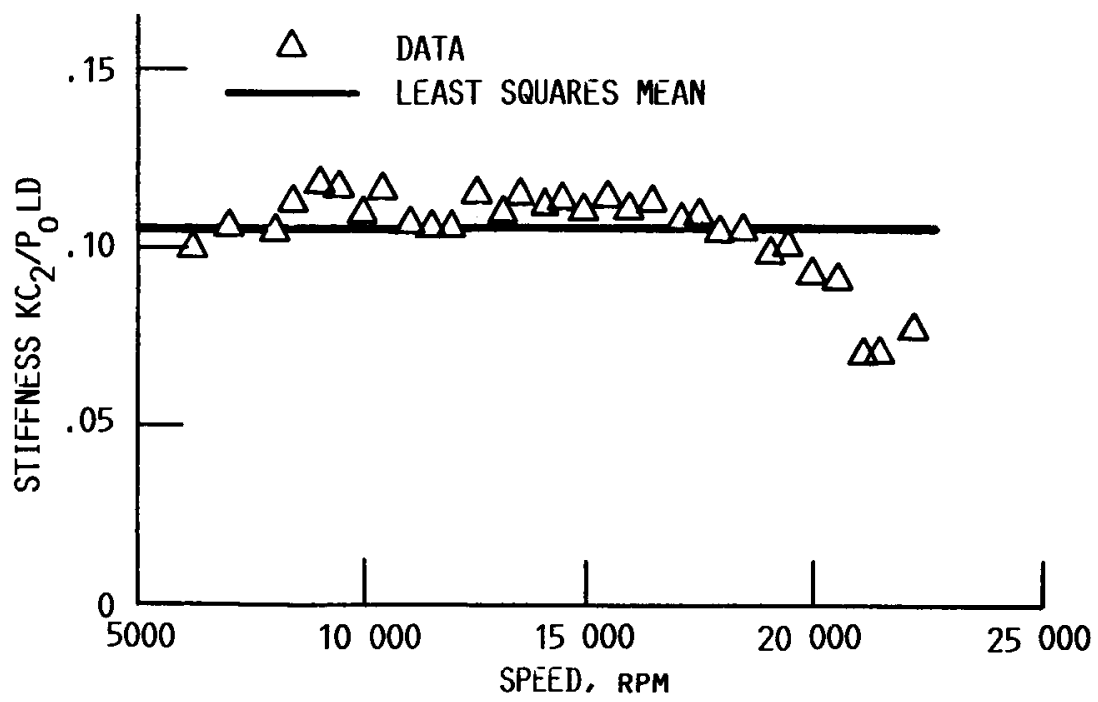

FIGURE 5. - STIFFNESS OF LOWER SEAL. UNBALANCE. $7.2 \mathrm{~g} \mathrm{~mm}$; PRESSURE RATI0, 6.2. 


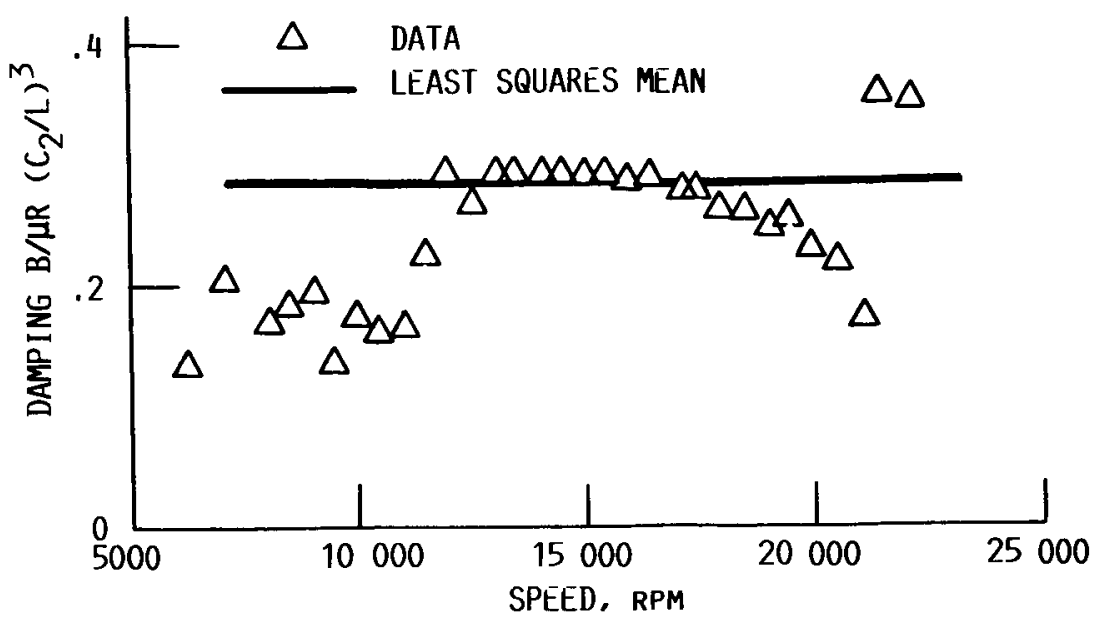

FIGURE 6. - DAMPING OF LOWER SEAL. UNBALANCE, $7.2 \mathrm{~g} \mathrm{~mm}$ : PRESSURE RATI0, 6.2.

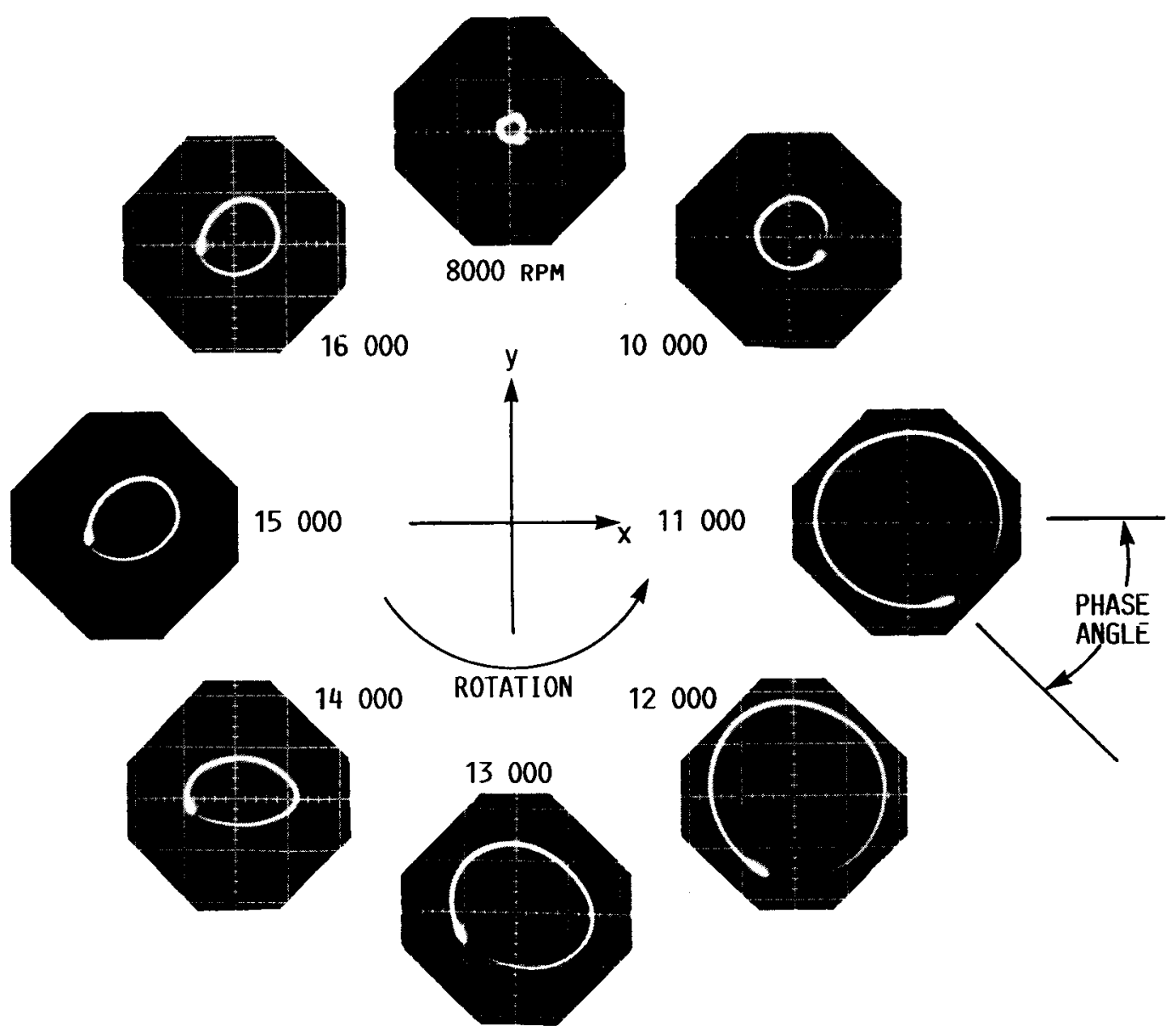

FIGURE 7. - SHAFT ORBITS, SHAFT 2, LOWER SEAL; $4.3 \mathrm{~g} \mathrm{~mm}$ UNBALANCE, PRESSURE RATI0, 3.4. 

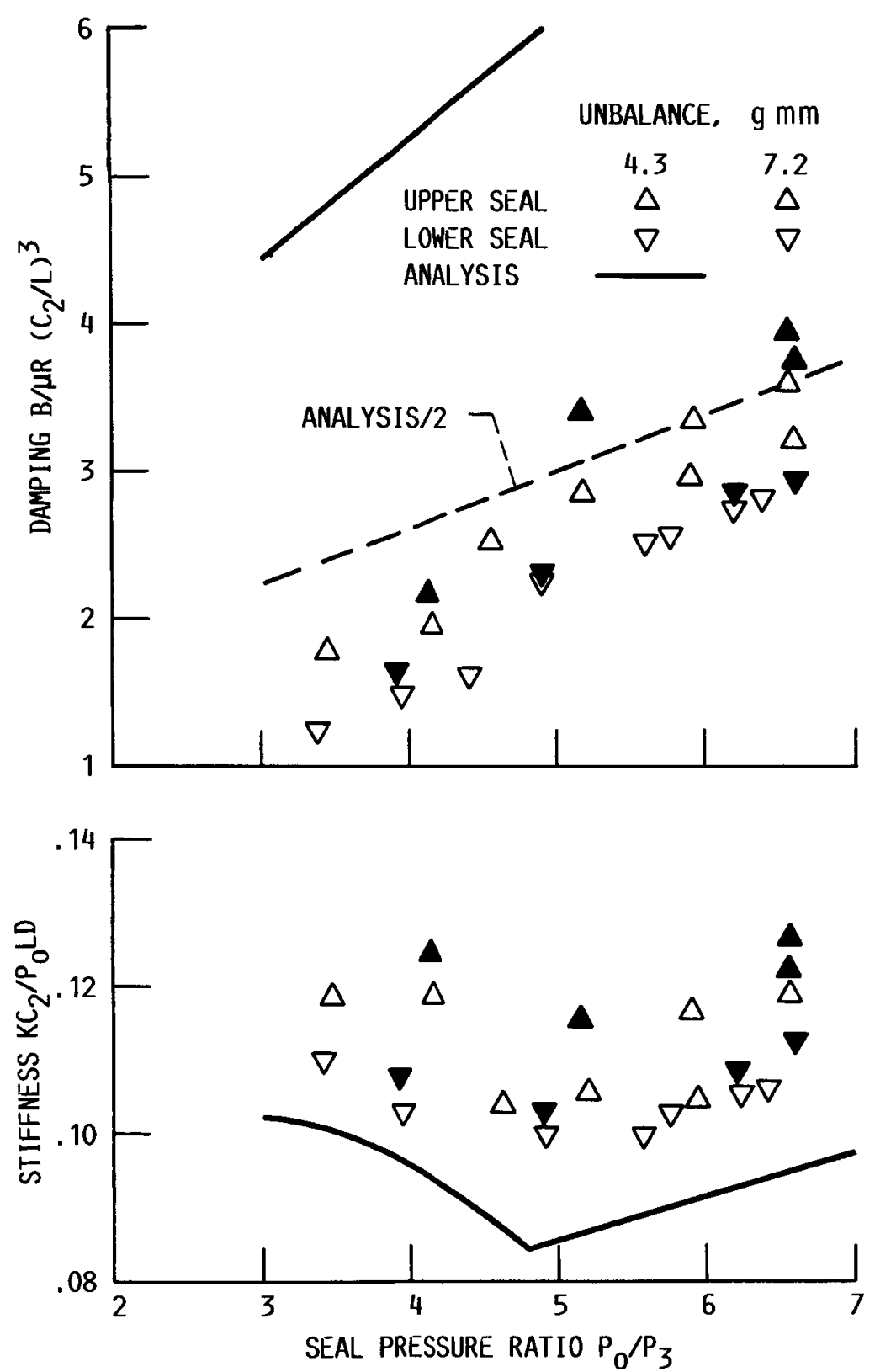

FIGURE 8. - STIFFNESS AND DAMPING FOR SHAFT 2. CLEARANCE, $0.026 \mathrm{~mm}$. 


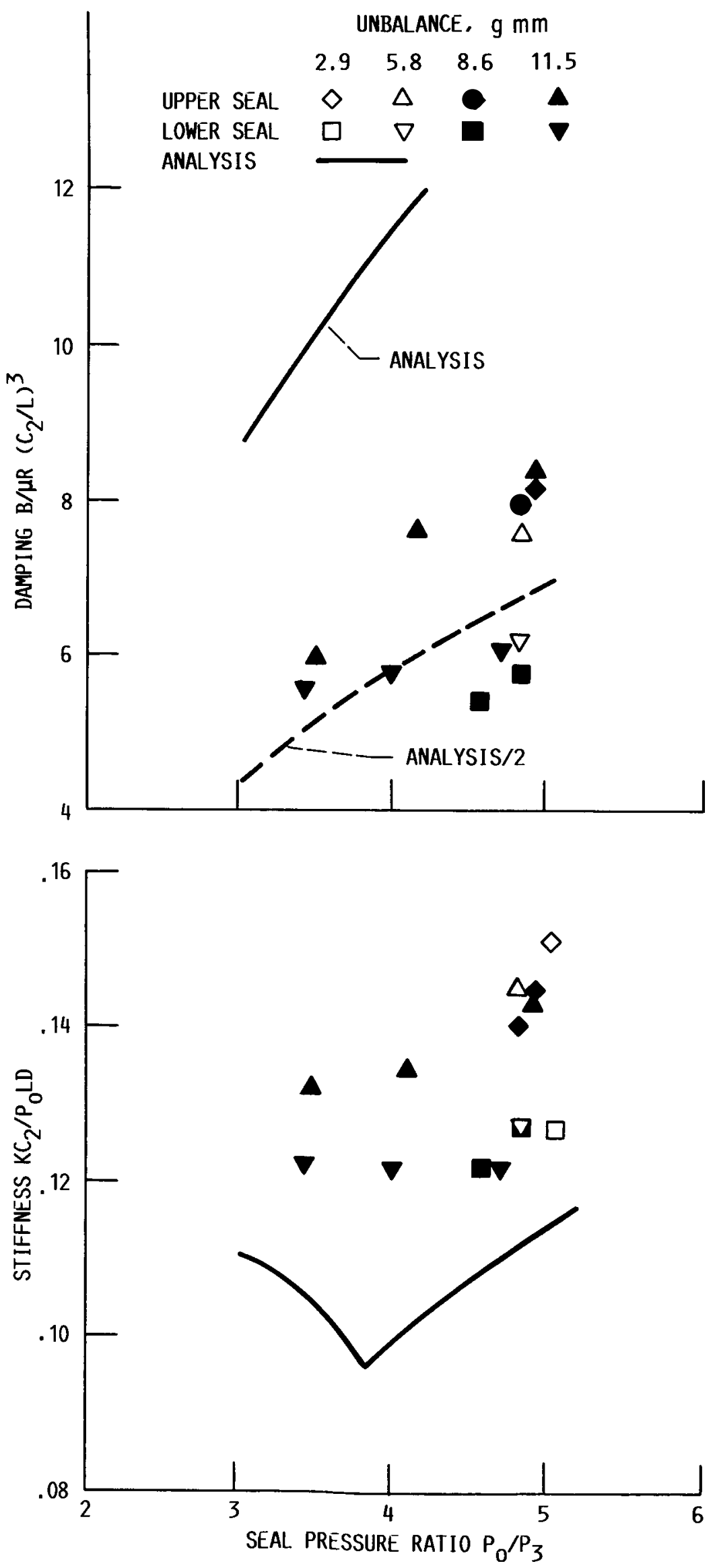

FIGURE 9. - STIFFNESS AND DAMPING FOR SHAFT 3. CLEARANCE, $0.040 \mathrm{~mm}$. 

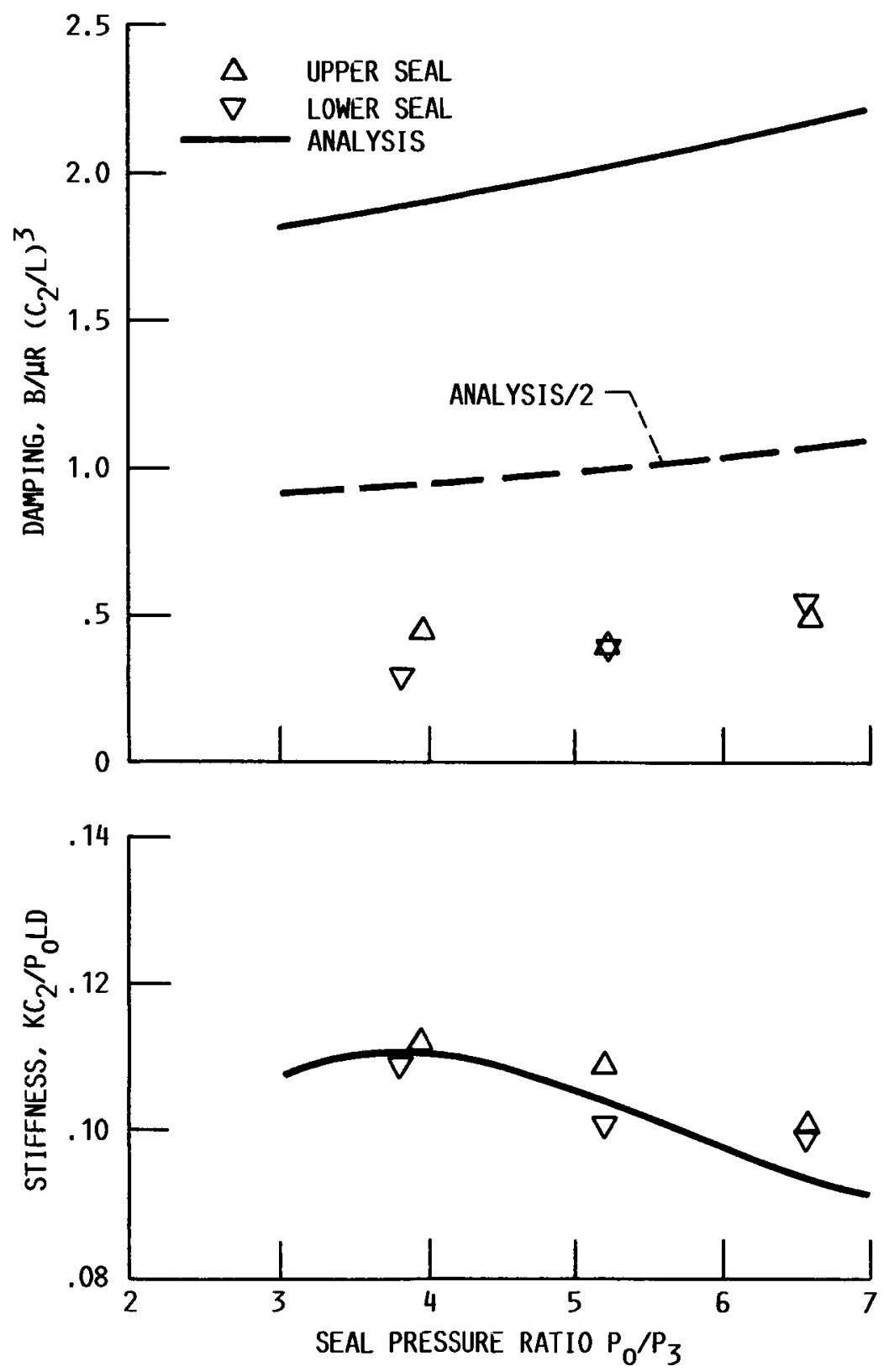

FIGURE 10. - STIFFNESS AND DAMPING FOR SHAFT 1. CLEARANCE, .014 MM: UNBALANCE, $2.9 \mathrm{~g} \mathrm{~mm}$. 


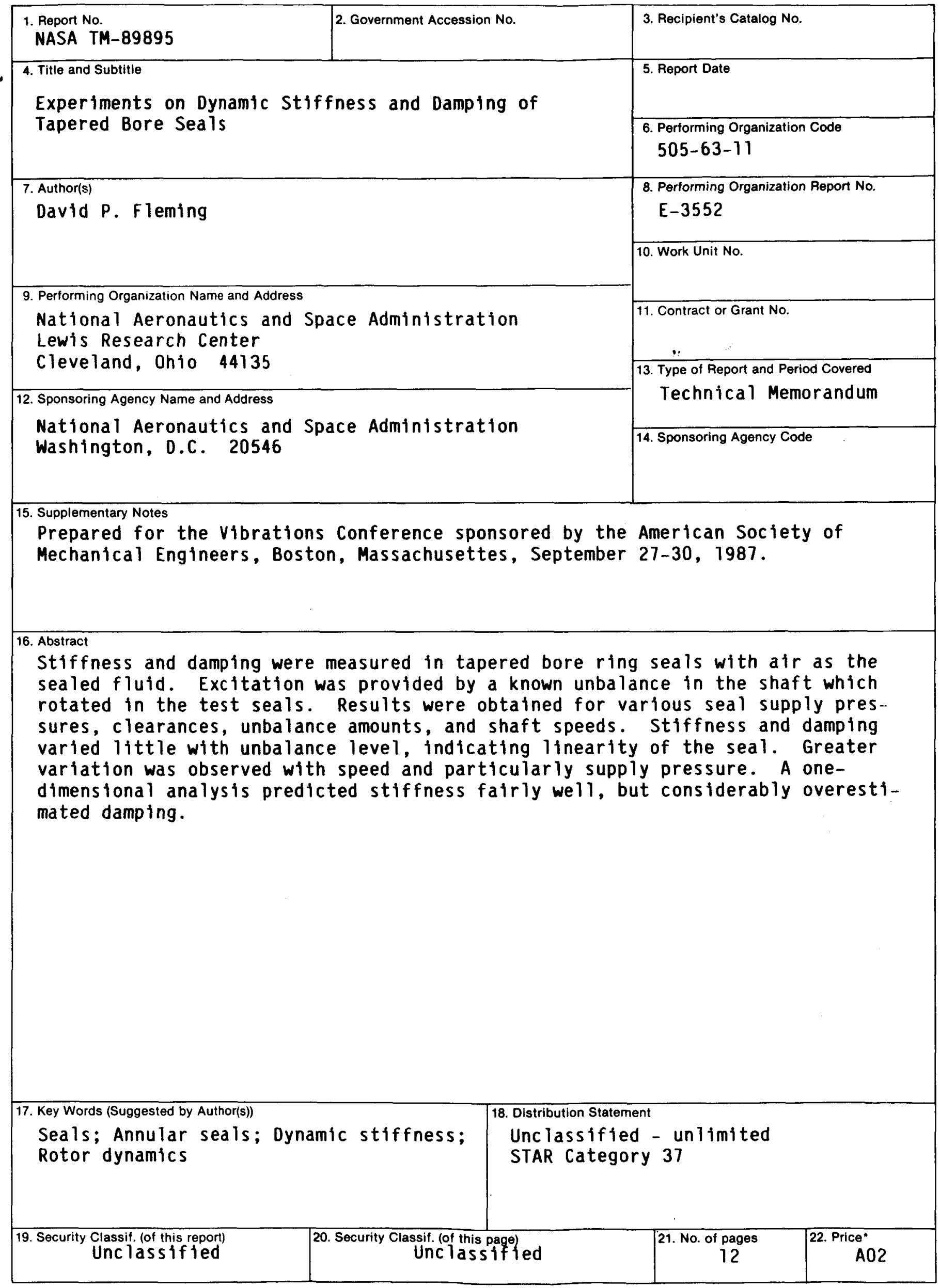

